\title{
Study of Auditory Brainstem Response in Tinnitus Patients with Normal Hearing
}

\section{Original Article}

\author{
Ossama Sobhy, Nadine Elbanby, Doaa Elmoazen \\ Department of Otorhinolaryngology, Audiovestibular Unit, Faculty of Medicine, Alexandria \\ University, Alexandria, Egypt.
}

\begin{abstract}
Introduction: Tinnitus is often associated with hearing loss, but it may occur in patients with normal hearing. However, normal hearing thresholds do not exclude cochlear damage. Tinnitus may be initiated by abnormal activity from the peripheral auditory system, but its progress and maintenance is due to the central nervous system involvement. For that reason, Auditory Brainstem Response (ABR) may contribute to clarify the origin of tinnitus.

Aim: The aim of this study is to evaluate the ABR waveform amplitude and latencies in tinnitus patients with normal hearing to explore the origin of tinnitus.

Results: Auditory brainstem response, recorded using ipsilateral rarefaction click stimuli at $80 \mathrm{dBnHL}$ in 10 normal hearing tinnitus adult patients and 10 matching controls, showed that Wave I amplitude was significantly reduced in the study group when compared to control group. The V/I amplitude ratio was significantly higher in the study group compared to control group. The absolute latency of wave I was significantly increased in the study group compared to control group. Interpeak I-V latency was significantly decreased in the study group compared to control group.

Conclusion: Tinnitus sufferers with normal audiometric thresholds might show ABR amplitude changes indicative of cochlear synaptopathy (reduced wave I amplitude) and compensated central responses (no reduction in wave $\mathrm{V}$ amplitude). The increased responsiveness of central regions might lead to tinnitus generation secondry to increased spontaneous activity.
\end{abstract}

Key Words: Auditory brainstem response, normal hearing, tinnitus.

Received: 25 September 2020, Accepted: 14 October 2020

Corresponding Author: Doaa Elmoazen, MD, Department of Otorhinolaryngology, Audiovestibular Unit, Faculty of Medicine, Alexandria University, Alexandria, Egypt, Tel.: +20 1224288678, E-mail: doaa.elmoazen@alexmed.edu.eg

ISSN: 2090-0740, 2021 Vol.22

\section{INTRODUCTION}

Tinnitus is the experience of sound sensation which is not related to any external source of stimulation or noise. It is a disturbing symptom that is often a main reason for referral to an otology clinic. ${ }^{[1]}$ Tinnitus is most common between 40 and 70 years of age, and occasionally occurs in children. ${ }^{[2]}$

Tinnitus severity varies from an occasional noise in ears, to an intolerable sound that pushes some subjects to contemplate suicide. ${ }^{[3]}$ Severe tinnitus is extremely disturbing because it impairs concentration and hearing and disrupts everyday activities and sleep. ${ }^{[4]}$

Tinnitus pathophysiology remains unclear. For many years, the ear was assumed to be the anatomical location for tinnitus but it is now evident that the tinnitus may be initiated by abnormal activity from the peripheral auditory system, however, its progress and maintenance is due to the central nervous system (CNS) involvement. Tinnitus is thought to result from hyperactivity and neuroplastic reorganization of cortical and subcortical auditory as well as non-auditory networks. ${ }^{[5,6]}$

The sensation of tinnitus may be associated with perceptual impairments at various levels of the auditory processing. Therefore auditory brainstem response (ABR) can be used in evaluating tinnitus patients for its objectivity in assessing the cochlear nerve and the auditory brainstem pathways. ${ }^{[7]}$ Some ABR findings were considered indices of central tinnitus. These indices included: abnormal morphology of ABR waveform and/or prolonged transmission time. Absolute and interpeak latencies (IPLs) of wave I, III, V and interaural latency difference of wave $\mathrm{V}$ could be prolonged.8 For that reason, ABR may contribute to clarify the origin of tinnitus. The aim of the current study is to evaluate the ABR waveform amplitude and latencies of tinnitus patients with normal hearing to explore the origin of tinnitus. 


\section{PATIENTS AND METHODS:}

\subsection{Subjects}

\section{Subjects were classified into two groups:}

Study group: Consisted of 10 adults complaining of bilateral tinnitus. All subjects had bilateral normal peripheral hearing in the frequency range of $250-8000 \mathrm{~Hz}$ including 3 and $6 \mathrm{kHz}$. This was defined as hearing threshold level equal to or below $25 \mathrm{dBHL}$ and bilateral normal middle ear functions. The exclusion criteria were age more than 60 years, hearing loss, disorders of the middle ear, history of psychological or neurological problems, history of neck problems and history of previous ototoxic medication.

Control group: consisted of 10 adults with bilateral normal peripheral hearing in the frequency range of 250 $8000 \mathrm{~Hz}$ including 3 and $6 \mathrm{kHz}$. All subjects had bilateral normal middle ear pressure. They were age and sex matched to the study group.

\subsection{Methods}

An informed consent was taken from each patient. All subjects were subjected to complete history taking, otoscopy to ensure normal external auditory canal, tympanometry to check the middle ear pressure and compliance and speech audiometry to exclude ANSD.

Assessment of pure tone audiometry were done using Madsen Itera II audiometer (Otometrics, Denmark). Air conduction was done for the frequency range of 250-8000 $\mathrm{Hz}$. Frequencies of 3 and $6 \mathrm{kHz}$ were also tested to exclude audiograms with minor dips at those frequencies. Bone conduction audiometry was done for the frequency range of $250-4000 \mathrm{~Hz}$.

ABR was done for all patients using Intelligent Hearing System (IHS, USA). ABR was recorded ipsilaterally with the positive recording electrode on the forehead, the reference electrode on the ipsilateral mastoid and the ground electrode on the contralateral mastoid. Rarefaction click stimuli were presented at $80 \mathrm{dBnHL}$, at a rate of 21.1/sec, through TDH-49p headphones. A total number of 1000 sweeps were obtained and a low pass filter with cut off frequency $3000 \mathrm{~Hz}$ and a high pass filter with cut off frequency $100 \mathrm{~Hz}$ were used.ABR waveforms were analyzed regarding wave I and $\mathrm{V}$ amplitudes, the absolute latencies of wave I, III and V and interpeak latencies of wave I-III, III-V and I-V .

\subsection{Statistical measures:}

Data were analyzed using IBM SPSS software package version 20.0. The Kolmogorov-Smirnov test was used to verify the normality of distribution. Significance of the obtained results was judged at the 5\% level. $P$-values $\leq 0.05$ were considered statistically significant.
For demographic data we used Chi-square test for categorical variables, Fisher's Exact or Monte Carlo correction as a correction for chi-square when more than $20 \%$ of the cells have expected count less than 5 . We used Student t-test for normally distributed quantitative variables, to compare pure tone audiometry thresholds, absolute latencies of wave I, III and V and IPLs I-III, III-V and I-V between the two studied groups.

For comparing wave I, V amplitudes and V/I amplitude ratio between the tinnitus and control groups we used Mann Whitney test for abnormally distributed quantitative variables, to compare between the two studied groups.

\section{RESULTS:}

Twenty subjects were examined. They were divided into two main groups. The study group consisted of 10 patients ( 4 males and 6 females). Age ranged from 24.0-44.40 years with a mean of $33.69 \pm 6.02$ years. All subjects had chronic bilateral tinnitus with bilateral normal peripheral hearing, including 3 and $6 \mathrm{kHz}$ of pure tone audiometry. Tympanometery and speech discrimination scores were normal in all subjects. The control group consisted of 10 subjects with normal hearing. They were 3 males and 7 females. Their age ranged from 27.20-49.20 years with the mean of $33.36 \pm 6.63$ years.

Comparing the thresholds of pure tone audiometry across the frequency range $250-8000 \mathrm{~Hz}$ revealed no significant difference between the two groups. Figure (1) shows the mean and standard deviation of pure tone audiometric thresholds across the tested frequency range in the two studied groups.

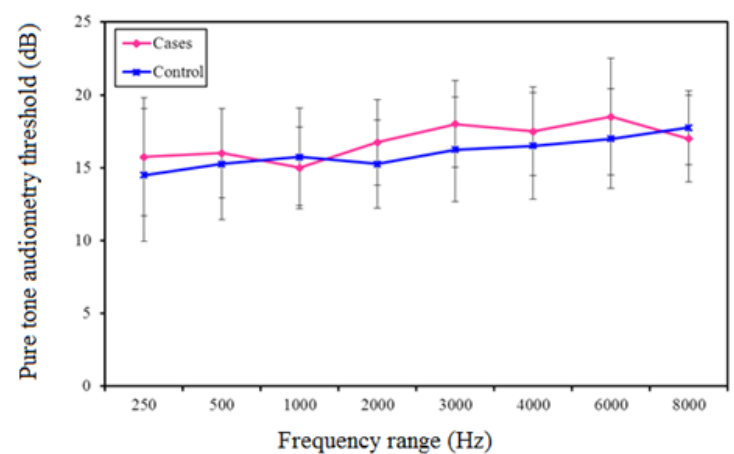

Fig. 1: Average pure tone audiograms of the two studied groups.

Comparing the right and left ears regarding wave I and $\mathrm{V}$ amplitudes and V/I amplitude ratio in each group, revealed no significant differences in either group (Table 1). Similarly, comparing wave I, III and V absolute latencies and IPLs of I-III, III-V and I-V in each group, revealed no significant differences between right and left ears (Table 2). The results from right and left ears were summed (20 ears) in each group for the subsequent analysis. 
Table 1: Comparison of the right and left ears amplitude of wave I and V and V/I amplitude ratio in each group

\begin{tabular}{|c|c|c|c|c|c|}
\hline & Amplitude $(\mu \mathrm{V})$ & Right & Left & Z & $p$ \\
\hline \multirow{3}{*}{ 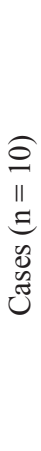 } & $\begin{array}{l}\text { Min. - Max. } \\
\text { Mean } \pm \text { SD. } \\
\text { Median }\end{array}$ & $\begin{array}{c}0.02-0.18 \\
0.07 \pm 0.05 \\
0.07\end{array}$ & $\begin{array}{c}0.04-0.14 \\
0.06 \pm 0.03 \\
0.05\end{array}$ & 0.296 & 0.767 \\
\hline & $\begin{array}{c}\text { Min. }- \text { Max. } \\
\text { Mean } \pm \text { SD. } \\
\text { Median }\end{array}$ & $\begin{array}{c}0.14-0.65 \\
0.40 \pm 0.17 \\
0.40\end{array}$ & $\begin{array}{c}0.21-0.69 \\
0.45 \pm 0.16 \\
0.45\end{array}$ & 0.919 & 0.358 \\
\hline & $\begin{array}{l}\text { V/I } \\
\text { Min. - Max. } \\
\text { Mean } \pm \text { SD. } \\
\text { Median }\end{array}$ & $\begin{array}{c}2.44-40.75 \\
13.49 \pm 12.66 \\
8.13\end{array}$ & $\begin{array}{c}3.27-24.65 \\
8.71 \pm 6.28 \\
6.57\end{array}$ & 0.764 & 0.445 \\
\hline \multirow{3}{*}{$\begin{array}{l}\widehat{O} \\
\| \\
\Xi \\
\Xi \\
0 \\
\Xi \\
0 \\
0\end{array}$} & $\begin{array}{l}\text { Min. - Max. } \\
\text { Mean } \pm \text { SD. } \\
\text { Median }\end{array}$ & $\begin{array}{c}0.06-0.46 \\
0.27 \pm 0.13 \\
0.25\end{array}$ & $\begin{array}{c}0.08-0.38 \\
0.23 \pm 0.09 \\
0.21\end{array}$ & 0.764 & 0.445 \\
\hline & $\begin{array}{l}\text { Min. - Max. } \\
\text { Mean } \pm \text { SD. } \\
\text { Median }\end{array}$ & $\begin{array}{c}0.11-0.53 \\
0.35 \pm 0.12 \\
0.36\end{array}$ & $\begin{array}{c}0.14-0.50 \\
0.35 \pm 0.10 \\
0.34\end{array}$ & 0.204 & 0.838 \\
\hline & $\begin{array}{l}\text { V/I } \\
\text { Min. - Max. } \\
\text { Mean } \pm \text { SD. } \\
\text { Median }\end{array}$ & $\begin{array}{c}0.85-2.70 \\
1.57 \pm 0.55 \\
1.49\end{array}$ & $\begin{array}{c}1.0-2.50 \\
1.75 \pm 0.52 \\
1.74\end{array}$ & 0.968 & 0.333 \\
\hline
\end{tabular}

$\mathrm{Z}, \mathrm{p}: \mathrm{Z}$ and $\mathrm{p}$ values for Wilcoxon signed ranks test for comparing between right and left

Table 2: Comparison of the right and left ears wave I, III and V absolute latencies and IPLs of I-III, III-V and I-V in each group

\begin{tabular}{|c|c|c|c|c|c|}
\hline & Latency (msec) & Right & Left & $\mathrm{t}$ & $p$ \\
\hline \multirow{6}{*}{ 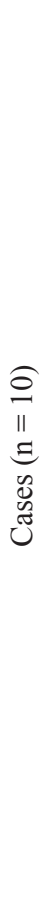 } & $\begin{array}{l}\text { Min. - Max. } \\
\text { Mean } \pm \text { SD. } \\
\text { Median }\end{array}$ & $\begin{array}{c}1.64-2.08 \\
1.83 \pm 0.13 \\
1.83\end{array}$ & $\begin{array}{c}1.6-2.08 \\
1.83 \pm 0.15 \\
1.83\end{array}$ & 0.048 & 0.963 \\
\hline & $\begin{array}{l}\text { III } \\
\text { Min. - Max. } \\
\text { Mean } \pm \text { SD. } \\
\text { Median }\end{array}$ & $\begin{array}{c}3.68-4.20 \\
3.91 \pm 0.19 \\
3.84\end{array}$ & $\begin{array}{c}3.73-4.15 \\
3.90 \pm 0.17 \\
3.87\end{array}$ & 0.033 & 0.974 \\
\hline & $\begin{array}{l}\text { Min. - Max. } \\
\text { Mean } \pm \text { SD. } \\
\text { Median }\end{array}$ & $\begin{array}{c}5.49-6.30 \\
5.77 \pm 0.27 \\
5.73\end{array}$ & $\begin{array}{c}5.5-6.30 \\
5.80 \pm 0.25 \\
5.77\end{array}$ & 1.748 & 0.114 \\
\hline & $\begin{array}{l}\text { I-III } \\
\text { Min. - Max. } \\
\text { Mean } \pm \text { SD. } \\
\text { Median }\end{array}$ & $\begin{array}{c}1.82-2.57 \\
2.08 \pm 0.23 \\
2.04\end{array}$ & $\begin{array}{c}1.8-2.55 \\
2.08 \pm 0.22 \\
2.06\end{array}$ & 0.164 & 0.873 \\
\hline & $\begin{array}{l}\text { III-V } \\
\text { Min. - Max. } \\
\text { Mean } \pm \text { SD. } \\
\text { Median }\end{array}$ & $\begin{array}{c}1.7-2.15 \\
1.87 \pm 0.13 \\
1.85\end{array}$ & $\begin{array}{c}1.69-2.15 \\
1.90 \pm 0.14 \\
1.91\end{array}$ & 1.791 & 0.107 \\
\hline & $\begin{array}{l}\mathrm{I}-\mathrm{V} \\
\text { Min. - Max. } \\
\text { Mean } \pm \text { SD. } \\
\text { Median }\end{array}$ & $\begin{array}{c}3.58-4.50 \\
3.94 \pm 0.31 \\
3.90\end{array}$ & $\begin{array}{c}3.50-4.70 \\
3.98 \pm 0.33 \\
3.89\end{array}$ & 0.896 & 0.393 \\
\hline
\end{tabular}




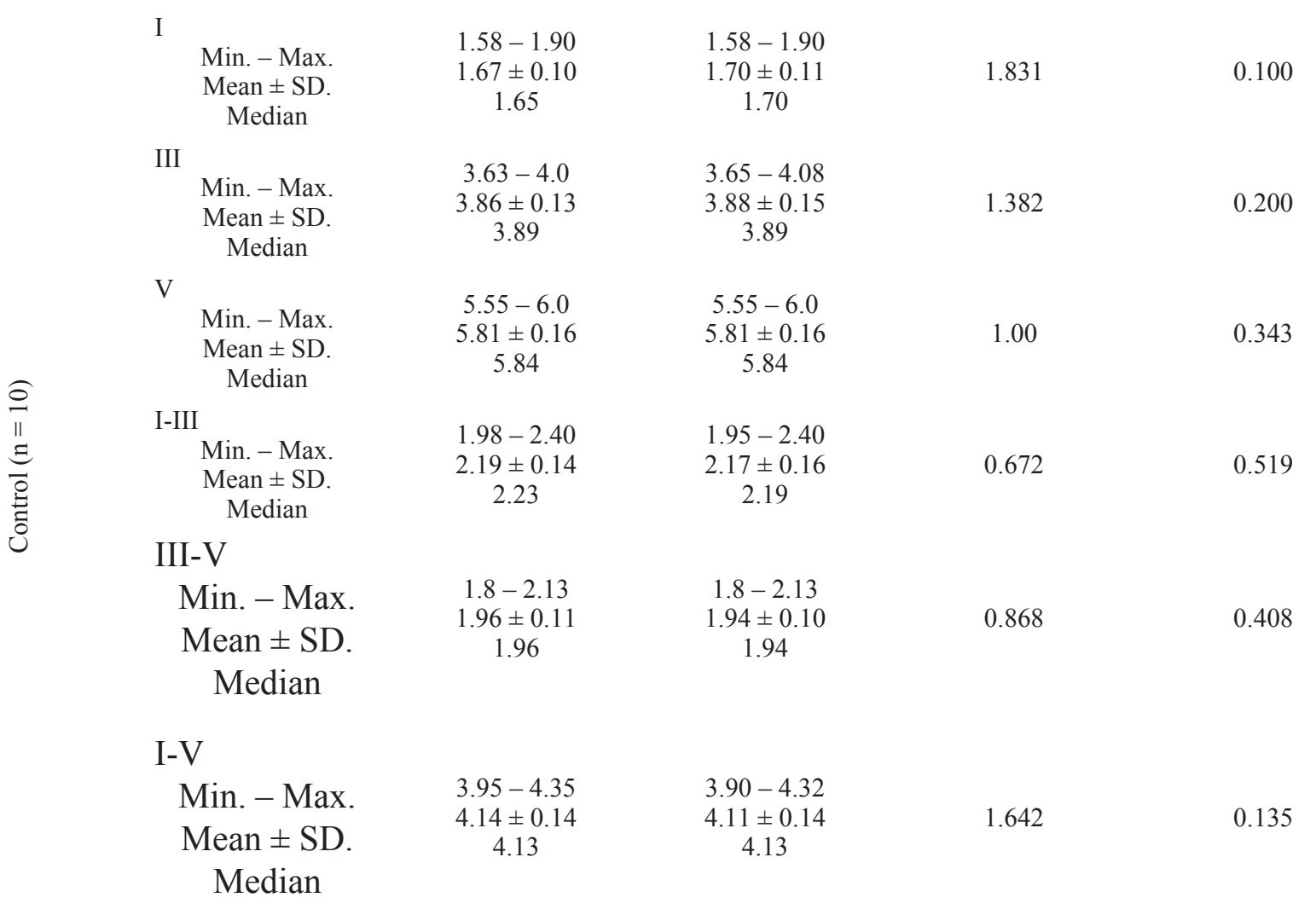

$\mathrm{t}, \mathrm{p}: \mathrm{t}$ and $\mathrm{p}$ values for Paired t-test for comparing between right and left

The amplitudes of wave I, V and V/I amplitude ratio were calculated and compared between the two studied groups using Mann Whitney test. The amplitude of wave I was found to be significantly reduced in the study group.
There was no significant difference in the amplitude of wave $\mathrm{V}$ between the two groups. The V/I ratio was significantly increased in the study group (Table 3 ).

Table 3: Comparison of the amplitude of wave I , V and V/I ratio in the two studied groups.

\begin{tabular}{|c|c|c|c|c|}
\hline Amplitude $(\mu \mathrm{V})$ & Cases $(n=20)$ & Control $(n=20)$ & $\mathrm{U}$ & $p$ \\
\hline $\begin{array}{c}\text { I } \\
\text { Min. - Max. } \\
\text { Mean } \pm \text { SD. } \\
\text { Median }\end{array}$ & $\begin{array}{c}0.02-0.18 \\
0.07 \pm 0.04 \\
0.06\end{array}$ & $\begin{array}{c}0.06-0.46 \\
0.25 \pm 0.11 \\
0.24\end{array}$ & $20.00^{*}$ & $<0.001^{*}$ \\
\hline $\begin{array}{c}\mathrm{V} \\
\text { Min. - Max. } \\
\text { Mean } \pm \text { SD. } \\
\text { Median }\end{array}$ & $\begin{array}{c}0.14-0.69 \\
0.42 \pm 0.16 \\
0.44\end{array}$ & $\begin{array}{c}0.11-0.53 \\
0.35 \pm 0.11 \\
0.34\end{array}$ & 144.50 & 0.133 \\
\hline $\begin{array}{c}\text { V/I } \\
\text { Min. - Max. } \\
\text { Mean } \pm \text { SD. } \\
\text { Median }\end{array}$ & $\begin{array}{c}2.44-40.75 \\
11.10 \pm 10.03 \\
\quad 6.82\end{array}$ & $\begin{array}{c}0.85-2.70 \\
1.66 \pm 0.53 \\
1.53\end{array}$ & $2.00^{*}$ & $<0.001^{*}$ \\
\hline
\end{tabular}

$\mathrm{U}, \mathrm{p}$ : $\mathrm{U}$ and $\mathrm{p}$ values for Mann Whitney test for comparing between the two groups

*: Statistically significant at $p \leq 0.05$

Applying student t-test to compare the absolute latencies of wave I, III and V and IPLs I-III, III-V and I-V between the study group and control group revealed significant difference in the absolute latency of wave I which was increased significantly in the study group. The IPL of I-V was significantly decreased in the study group. There was no significant difference between the two studied groups in the absolute latencies of wave III and V nor the I-III and III-V IPLs (Table 4). 
Table 4: Comparison of latency in the two studied groups.

\begin{tabular}{|c|c|c|c|c|}
\hline Latency (msec) & Cases $(n=20)$ & Control $(n=20)$ & $\mathrm{t}$ & $p$ \\
\hline \multicolumn{5}{|l|}{ I } \\
\hline Min. - Max. & $1.60-2.08$ & $1.58-1.90$ & $3.722^{*}$ & $0.001^{*}$ \\
\hline Mean \pm SD & $1.83 \pm 0.14$ & $1.69 \pm 0.10$ & & \\
\hline Median & 1.83 & 1.68 & & \\
\hline \multicolumn{5}{|l|}{ III } \\
\hline Min. - Max. & $3.68-4.20$ & $3.63-4.08$ & 0.781 & 0.440 \\
\hline Mean \pm SD & $3.90 \pm 0.18$ & $3.87 \pm 0.14$ & & \\
\hline Median & 3.87 & 3.89 & & \\
\hline \multicolumn{5}{|l|}{$\mathrm{V}$} \\
\hline Min. - Max. & $5.49-6.30$ & $5.55-6.0$ & 0.382 & 0.705 \\
\hline Mean \pm SD & $5.79 \pm 0.26$ & $5.81 \pm 0.16$ & & \\
\hline Median & 5.75 & 5.84 & & \\
\hline \multicolumn{5}{|l|}{ I-III } \\
\hline Min. - Max. & $1.80-2.57$ & $1.95-2.40$ & 1.731 & 0.091 \\
\hline Mean \pm SD & $2.08 \pm 0.22$ & $2.18 \pm 0.15$ & & \\
\hline Median & 2.04 & 2.20 & & \\
\hline \multicolumn{5}{|l|}{ III-V } \\
\hline Min. - Max. & $1.69-2.15$ & $1.80-2.13$ & 1.757 & 0.087 \\
\hline Mean \pm SD & $1.88 \pm 0.13$ & $1.95 \pm 0.10$ & & \\
\hline Median & 1.88 & 1.95 & & \\
\hline \multicolumn{5}{|l|}{$\mathrm{I}-\mathrm{V}$} \\
\hline Min. - Max. & $3.50-4.70$ & $3.90-4.35$ & $2.149^{*}$ & $0.041^{*}$ \\
\hline Mean \pm SD & $3.96 \pm 0.31$ & $4.12 \pm 0.14$ & & \\
\hline Median & 3.89 & 4.13 & & \\
\hline
\end{tabular}

$\mathrm{t}, \mathrm{p}$ : $\mathrm{t}$ and $\mathrm{p}$ values for Student $\mathrm{t}$-test for comparing between the two groups

$*$ : Statistically significant at $p \leq 0.05$

\section{DISCUSSION}

Tinnitus pathophysiology is still not clear, although, various origins and mechanism have been described in the literature. ${ }^{[9]}$ Multiple mechanisms may be present in a single individual with tinnitus. ${ }^{[10]}$ Generally, sensory neural hearing loss (SNHL) has a major role as an initiating event that triggers neurophysiological processes, which are perceived as tinnitus. ${ }^{[11]}$ On the other hand, it is also known that some tinnitus patients do not show any hearing loss in the conventional audiograms. ${ }^{[12,13]}$

The two studied groups had normal peripheral hearing by conventional audiometry. There was no significant difference in the thresholds of pure tone audiometry across the frequency range $250-8000 \mathrm{~Hz}$ including 3000 and $6000 \mathrm{~Hz}$. It has been argued that a normal pure tone audiogram does not exclude cochlear damage. Tinnitus patients with normal audiograms had higher incidence of outer hair cell damage and impaired hearing thresholds in the extended HF region as compared to control groups. ${ }^{[14]}$
In the current study, ABR wave amplitudes in both ears were compared between the study group and the control group. Significantly reduced amplitudes of wave I were found in the study group. Lemaire and Beutter also reported reduced wave I and III amplitudes in normal hearing tinnitus patients. ${ }^{[15]}$ Schaette and McAlpine and Gu et al. showed similar results of reduced wave I amplitudes at high levels (80-90 dBSPL) in tinnitus patients with normal hearing compared to matched non tinnitus controls. ${ }^{[16,17]}$

Kujawa and Liberman found that the amplitude of ABR wave I of mice significantly decreased at moderately- high levels (above $70 \mathrm{~dB}$ ) up to 2 months following noise exposure even when auditory thresholds were recovered to normal. ${ }^{[18]}$ In addition, damage to the synaptic ribbons of inner hair cells and spiral ganglion cells were found, suggesting that reduced wave I amplitude may be indicative of auditory nerve (AN) deafferenation. The term "cochlear synaptopathy" was suggested to describe 
damage at the cochlear synapse without the loss of hair cells resulting in "hidden hearing loss", without elevation of the audiometric thresholds. ${ }^{[19,20]}$

ABR wave amplitude may be altered by the number of neural components activated by sound and the level of synchronization between them. The reduction in amplitude of wave I noted previously at high intensities might indicate loss of neural fibers as well as a decrease of synchronization. ${ }^{[15]}$

There was no significant difference in amplitude of wave $\mathrm{V}$ between the two studied groups in the current study. Similarly, Schaette and McAlpine found no significant difference in wave $\mathrm{V}$ amplitude in normal hearing tinnitus patients and suggested that the normal wave $\mathrm{V}$ amplitude, despite a reduction in wave $\mathrm{I}$, is due to increased neural responsiveness of the central auditory system to compensate for the reduced activity of the AN. ${ }^{[16]}$ Schaette and McAlpine demonstrated a deficit in AN function in subjects with tinnitus and apparently normal hearing. This was demonstrated as a reduction in nerve output at high sound levels, indicating deafferentation of high threshold nerve fibers. This deficit appeared to be compensated for at the level of the brainstem. This finding supported the view that tinnitus was promoted by homeostatic mechanisms which acted to normalize levels of neural activity in the central auditory system. ${ }^{[16]}$

$\mathrm{Gu}$ et al. found higher wave $\mathrm{V}$ amplitudes in normal hearing tinnitus patients but it was suggested that the increased amplitude of wave $\mathrm{V}$ is an artifact from the use of a lower frequency filter cutoff. ${ }^{[17]}$

On the other hand the study of Barnea et al. reported normal ABR amplitudes in tinnitus subjects with normal audiograms, compared to clinical norms but not with a closely matched control group, which might not be suitable for detecting subtle ABR abnormalities. ${ }^{[1]}$

In the current study the amplitude ratio of V/I was significantly higher in the study group compared to the control group mainly due to the significantly reduced wave I amplitude. Nemati et al. reported significant enhancement in V/I amplitude ratio in normal hearing tinnitus patients. ${ }^{[21]}$ Kehrle et al., compared tinnitus and non tinnitus subjects with clinically normal thresholds and reported an enhanced V/I amplitude ratio in tinnitus subjects. ${ }^{[22]}$ While they did not report whether the enhanced amplitude ratio was due to a reduction in wave I, an elevation in wave $\mathrm{V}$ or a mixture of both. The report of Schaette and McAlpine indicated that reduced wave I was a factor. ${ }^{[16]}$
In summary, changes in wave I might indicate peripheral damage and the following wave modifications might reflect central compensation mechanisms such as increased higher neural synchrony in tinnitus. Based on the previous findings, tinnitus sufferers with normal audiometric thresholds might show ABR amplitude changes indicative of cochlear synaptopathy (reduced wave I) and compensated central responses (normal or elevated wave V). The increased responsiveness of central regions might lead to tinnitus generation secondry to increased spontaneous activity.

Based on computational models of tinnitus development, it was hypothesized that deafferentation of a substantial fraction of the AN fibers could trigger the development of a neural correlate of tinnitus in central auditory structures in the form of homeostatic plasticity effectively amplifying spontaneous neural activity and increasing the central neural gain leading to the perception of tinnitus. However, it remains unclear where in the auditory system tinnitus is first generated, as presumed neural correlates have been observed at all stages of the central pathways. ${ }^{[18]}$

Comparing the absolute latencies of wave I, III and $\mathrm{V}$ and IPLs I-III, III-V and I-V between the two studied groups, the absolute latency of wave I was found to be significantly increased in the study group and I-V IPL was found to be significantly decreased in the study group. There was no significant difference between the two studied groups in the absolute latencies of wave III and V nor in IPLs I-III and III-V.

Ikner and Hassen reported longer wave I, III, V and III-V IPL in normal hearing tinnitus patients. ${ }^{[23]}$ Kehrle et al. also reported longer wave I, III, V and III-V in normal hearing tinnitus patients. ${ }^{[22]}$ Rosenhall and Axelsson reported longer wave I, III and V in normal hearing tinnitus patients. ${ }^{[24]}$ Cartocci et al. reported longer wave $\mathrm{V}$ and III-V IPL in normal hearing tinnitus patients. ${ }^{[25]}$ Those authors showed two patterns of abnormalities. The first pattern was a prolongation of wave I accompanied by a prolongation of wave III and V, with normal IPLs, a finding which is consistent with a lesion in the peripheral auditory system. ${ }^{[26]}$ The other is a lengthening of the IPLs reflecting an increased neural conduction time in the brainstem. ${ }^{[26]}$ Alternatively, Singh et al. reported longer wave I, shorter wave V, shorter I-V IPL in normal hearing tinnitus patients. ${ }^{[27]}$ Shortening of wave V latency was interpreted as hyperactivity in the ascending auditory pathway. ${ }^{[27]}$

On the other hand several studies found no latency differences in normal hearing tinnitus patients. ${ }^{[1,28-32]}$ 
Some researchers attributed the absence of significant latency differences of ABR components to the type of stimuli used in recording these responses. They proposed that click stimuli may cause masking effect on abnormal spontaneous activity of auditory nerve centers and pathways, leading to absolute and IPLs similar to normal subjects. ${ }^{[22,31]}$

The prolongation of wave I occurs in ears with cochlear hearing loss and has been reported since 1977. ${ }^{[33]}$ Tinnitus patients included in the current study with hearing thresholds in the clinically normal range showing prolongation of wave I, may indicate hair cell damage ${ }^{[34]}$, suggesting that hearing impairment may be present. They may possibly have SNHL at frequencies greater than the $8000 \mathrm{~Hz}$ not tested by the conventional audiometry. ${ }^{[35]}$ Thus conventional audiogram might not be sufficiently sensitive for assessing cochlear function. It is also likely that the prolonged latency reflects slow synaptic processes in the organ of Corti or decreased neural conduction velocity in the first auditory neuron. ${ }^{[22]}$

In animal studies, mice subjected to mild acoustic trauma displayed a temporary shift in hearing thresholds but a permanent deafferentation of some $50-60 \%$ of the AN fibers in the high frequency region of the cochlea. This suggests that noise induced deafferentation mainly affects high threshold AN fibers, while sufficient numbers of low threshold AN fibers remain responsive to sound. ${ }^{[18]}$ Although this hidden hearing loss may not be measurable by conventional pure tone audiometry, it may have consequences for the coding of sounds at moderate and high levels.

Additionally, demonstration of normal hearing thresholds do not necessarily exclude absence of cochlear damage since normal hearing thresholds can be accompanied by impaired function of efferent fibers that project from the brainstem to the cochlea. ${ }^{[36-39]}$

\section{CONCLUSION}

Tinnitus patients with normal hearing may have hidden hearing loss that was not yet visible on the audiogram. This hidden hearing loss enhance the central auditory structural changes which in turn progress and maintain the tinnitus perception. ABR should be included in tinnitus evaluation test battery. It might show amplitude changes indicative of cochlear synaptopathy (reduced wave I amplitude) and compensated central responses. The altered responsiveness of central regions might lead to tinnitus generation secondry to increased spontaneous activity.

\section{CONFLICT OF INTEREST}

There are no conflicts of interest

\section{LIST OF ABBREVIATIONS:}

$\begin{array}{ll}\text { ABR } & \text { Auditory Brainstem Response } \\ \text { AN } & \text { Auditory Nerve } \\ \mathrm{dB} & \text { Decibel } \\ \mathrm{CNS} & \text { Central Nervous System } \\ \mathrm{IPL} & \text { Interpeak Latencies } \\ \mathrm{kHz} & \text { Kilo Hertz } \\ \mathrm{nHL} & \text { Normalized Hearing Level } \\ \mathrm{SNHL} & \text { Sensory Neural Hearing Loss } \\ \mathrm{SPL} & \text { Sound Pressure Level }\end{array}$

REFERENCES

1. Barnea G, Attias J, Gold S, Shahar A. Tinnitus with normal hearing sensitivity: extended high-frequency audiometry and auditory-nerve brain-stem-evoked responses. Audiology. 1990; 29(1):36-45.

2. Schleuning AJ. 2nd. Management of the patient with tinnitus. Med Clin North Am. 1991; 75(6):1225-1237.

3. Meyerhoff WL, Cooper JC. Tinnitus. In: Paparella MM (ed). Otolaryngology. $3^{\text {rd }}$ ed. Philadelphia: Saunders; 1991:1169-1175.

4. Heller AJ. Classification and epidemiology of tinnitus. Otolaryngol Clin North Am. 2003; 36(2):239-248.

5. Weisz N, Wienbruch C, Dohrmann K, Elbert T. Neuromagnetic indicators of auditory cortical reorganization of tinnitus. Brain.2005; 128:27222731 .

6. Eggermont JJ, Roberts LE. The neuroscience of tinnitus. Trends Neurosci. 2004; 27(11):676-682.

7. Dobbie RA. Physiological techniques used in the assessment of the auditory system. In: Keith R (ed). Auditory for the Physician. Baltimore: Williams \& Wilkins; 1980:14.

8. Milloy V, Fournier P, Benoit D, Norena A, Koravand A. Auditory Brainstem Responses in Tinnitus: A Review of Who, How, and What? Front Aging Neurosci. 2017; 9:237.

9. Henry JA, Roberts LE, Caspary DM, Theodoroff SM, Salvi RJ. Underlying mechanisms of tinnitus: review 
and clinical implications. J Am Acad Audiol. 2014; 25(1):5-22.

10. Gray WC, Jastreboff PJ. Medical aspects of a neurophysiological approach to tinnitus. In: Gray WC, Jastreboff PJ (ed). Abstracts of the eighteenth annual midwinter research meeting of the Association for Research in Otolaryngology. Florida: St. Petersburg Beach; 1995:5-9.

11. König O, Schaette R, Kempter R, Gross M. Course of hearing loss and occurrence of tinnitus. Hear Res. 2006; 221(1-2):59-64.

12. Medeiros I, Sanchez TG, Levy CP, Santos H, Ramalho JR. Tinnitus in normal hearing patients: an uncommon group. Otolaryngol Head Neck Surg. 2004; 131(2):250.

13. Spankovich C, Gonzalez VB, Su D, Bishop CE. Self reported hearing difficulty, tinnitus, and normal audiometric thresholds, the National Health and Nutrition Examination Survey 1999-2002. Hear Res. $2018 ; 358: 30-36$.

14. Fabijanska A, Smurzynski J, Kochanek K, Bartnik G, Raj-Koziak D, Skarzynski H. The influence of high frequency hearing loss on the distortion product otoacoustic emissions in tinnitus subjects with normal hearing threshold $(0,25-8 \mathrm{kHz})$. Otolaryngol Pol. 2012; 66(5):318-321.

15. Lemaire MC, Beutter P. Brainstem auditory evoked responses in patients with tinnitus. Audiology.1995; 34(6):287-300.

16. Schaette R, McAlpine D. Tinnitus with a normal audiogram: physiological evidence for hidden hearing loss and computational model. J Neurosci. 2011; 31(38):13452-13457.

17. Gu JW, Herrmann BS, Levine RA, Melcher JR. Brainstem auditory evoked potentials suggest a role for the ventral cochlear nucleus in tinnitus. J Assoc Res Otolaryngol.2012; 13(6):819-833.

18. Kujawa SG, Liberman MC. Adding insult to injury: cochlear nerve degeneration after "temporary" noiseinduced hearing loss. J Neurosci. 2009; 29(45):1407714085 .

19. Knipper M, Hofmeier B, Singer W, Wolpert S, Klose U, Rüttigeret L (2019) Differentiation of cochlear synaptopathies into different hearing disorders. ENT 67, 406-416

20. Liberman MC, Kujawa SG. Cochlear synaptopathy in acquired sensorineural hearing loss: Manifestations and mechanisms. Hear Res. 2017; 349:138-147.
21. Nemati S, Faghih Habibi A, Panahi R, Pastadast M. Cochlear and brainstem audiologic findings in normal hearing tinnitus subjects in comparison with non-tinnitus control group. Acta Med Iran. 2014; 52(11):822-826.

22. Kehrle HM, Granjeiro RC, Sampaio AL, Bezerra R, Almeida VF, Oliveira CA. Comparison of auditory brainstem response results in normal-hearing patients with and without tinnitus. Arch Otolaryngol Head Neck Surg. 2008; 134(6):647-651.

23. Ikner CL, Hassen AH. The effect of tinnitus on ABR latencies. Ear Hear. 1990; 11(1):16-20.

24. Rosenhall U, Axelsson A. Auditory brainstem response latencies in patients with tinnitus. Scand Audiol. 1995; 24(2):97-100.

25. Cartocci G, Attanasio G, Fattapposta F, Locuratolo N, Mannarelli D, Filipo R. An electrophysiological approach to tinnitus interpretation. Int Tinnitus $\mathrm{J}$. 2012; 17(2):152-157.

26. Møsller AR. Pathophysiology of tinnitus. Ann Otol Rhinol Laryngol. 1984; 93(1):39-44.

27. Singh S, Munjal SK, Panda NK. Comparison of auditory electrophysiological responses in normalhearing patients with and without tinnitus. J Laryngol Otol. 2011; 125(7):668-672.

28. Attias J, Pratt H, Reshef I, Bresloff I, Horowitz G, Polyakov A, Shemesh Z. Detailed analysis of auditory brainstem responses in patients with noise-induced tinnitus. Audiology. 1996; 35(5):259-270.

29. Gilles A, Schlee W, Rabau S, Wouters K, Fransen E, Van de Heyning P. Decreased Speech-In-Noise Understanding in Young Adults with Tinnitus. Front Neurosci. 2016; 10:288.

30. Santos-Filha VA, Samelli AG, Matas CG. Noiseinduced tinnitus: auditory evoked potential in symptomatic and asymptomatic patients. Clinics (Sao Paulo). 2014; 69(7):487-490.

31. McKee GJ, Stephens SD. An investigation of normally hearing subjects with tinnitus. Audiology. 1992; 31(6):313-317.

32. Nemati S, Faghih Habibi A, Panahi R, Pastadast M. Cochlear and brainstem audiologic findings in normal hearing tinnitus subjects in comparison with non-tinnitus control group. Acta Med Iran. 2014; 52(11):822-826. 
33. Coats AC, Martin JL. Human auditory nerve action potentials and brain stem evoked responses: effects of audiogram shape and lesion location. Arch Otolaryngol. 1977; 103(10):605-622.

34. Job A, Raynal M, Kossowski M. Susceptibility to tinnitus revealed at $2 \mathrm{kHz}$ range by bilateral lower DPOAEs in normal hearing subjects with noise exposure. Audiol Neurootol. 2007; 12(3):137-144.

35. Elmoazen D, Kozou H, Mohamed A. High frequency audiometry in tinnitus patients with normal hearing in conventional audiometry. Egypt J Otolaryngol. 2018; 34(4):308-315.

36. Jacobson M, Kim S, Romney J, Zhu X, Frisina RD. Contralateral suppression of distortion-product otoacoustic emissions declines with age: a comparison of findings in CBA mice with human listeners. Laryngoscope. 2003; 113(10):1707-1713.
37. Kim S, Frisina DR, Frisina RD. Effects of age on contralateral suppression of distortion product otoacoustic emissions in human listeners with normal hearing. Audiol Neurootol. 2002; 7(6):348-357.

38. Zettel ML, Zhu X, O'Neill WE, Frisina RD. Agerelated decline in $\mathrm{Kv} 3.1 \mathrm{~b}$ expression in the mouse auditory brainstem correlates with functional deficits in the medial olivocochlear efferent system. J Assoc Res Otolaryngol. 2007; 8(2):280-293.

39. Zhu X, Vasilyeva ON, Kim S, Jacobson M, Romney J, Waterman MS, Tuttle D, Frisina RD. Auditory efferent feedback system deficits precede age-related hearing loss: contralateral suppression of otoacoustic emissions in mice. J Comp Neurol. 2007; 503(5):593604. 